\title{
DIREITO À MORADIA E CONCILIAÇÃO JUDICIAL DE CONFLITOS COLETIVOS POSSESSÓRIOS: A EXPERIÊNCIA DE PORTO ALEGRE
}

\author{
(RIGHT TO HOUSING AND JUDICIAL CONCILIATION OF COLLECTIVE LAND TENURE \\ CONFLICTS: THE EXPERIENCE OF PORTO ALEGRE)
}

Cláudio Ari Mello ${ }^{1}$

\begin{abstract}
Resumo
O artigo descreve a experiência desenvolvida pelo Poder Judiciário em Porto Alegre, com a criação de uma equipe especializada para tentar a conciliação em ações judiciais envolvendo conflitos possessórios coletivos urbanos. O texto descreve a estrutura do projeto, expõe alguns de seus resultados, analisa criticamente algumas vantagens e desafios do projeto e propõe a adoção de algumas medidas que podem melhorar a performance da conciliação judicial em conflitos envolvendo ocupações urbanas, baseadas em modelo empregado pela Corte Constitucional da África do Sul. O artigo sustenta que o Código de Processo Civil de 2015 instituiu um dever judicial de tentar a conciliação em ações possessórias coletivas e, assim, criou uma posição jurídica subjetiva que agora pertence ao conteúdo normativo do direito fundamental à moradia. Por consequência, a tentativa de conciliação judicial nas ações possessórias coletivas passou a ser um direito dos ocupantes de áreas urbanas.
\end{abstract}

Palavras-chave: Direito à Moradia; Conflitos Possessórios Coletivos; Conciliação Judicial; Direitos Fundamentais; Acesso à Justiça.

\section{Abstract}

The article describes the experience developed by the Judiciary Power in Porto Alegre, with the creation of a specialized staff to try the conciliation in lawsuits concerning collective conflicts on urban land tenure. The text describes the structure of the project, expounds some of its outcomes, analyzes critically some advantages and challenges of the project and proposes the adoption of some measures that could improve the performance of judicial conciliation in conflicts about urban occupations, based on a model deployed by the South African Constitutional Court. The article sustains that the 2015 Code of Civil Procedure instituted a judicial duty to attempt the conciliation in collective land tenure actions; thus it created a subjective juridical position that now belongs to the normative content of the fundamental right to housing. Accordingly, the attempt of conciliation in the collective land tenure lawsuits has become a right of the occupiers of urban areas.

Keywords: Right to Housing; Collective Land Tenure Conflicts; Judicial Conciliation; Fundamental Rights; Access to Justice.

\footnotetext{
1 Professor da Escola de Direito da Pontifícia Universidade Católica do Rio Grande do Sul. Doutor em Teoria do Direito pela UFRGS e mestre em Direito do Estado pela PUCRS. E-mail: claudio.ari@hotmail.com
} 


\section{INTRODUÇÃO}

Um dos grandes desafios que a positivação do direito fundamental à moradia impôs à experiência jurídica consiste na possibilidade de encontrarmos mecanismos para promover a sua tutela judicial de maneira efetiva. Tratando-se de um direito social, um dos últimos a serem incluídos na lista de direitos fundamentais da Constituição Federal de 1988, naturalmente a sua eficácia jurídica predominante deve ser a de garantir pretensão a prestações estatais. A dogmática constitucional reconhece que o principal conteúdo normativo dos direitos sociais ou prestacionais reside precisamente na imputação de obrigações positivas aos órgãos públicos que sejam capazes de satisfazer o bem jurídico garantido pelo direito, seguindo a tradição do conceito teórico de direito subjetivo, que considera a tutela judicial uma propriedade inerente à natureza mesma do conceito. ${ }^{2}$

A proteção judicial dos direitos sociais avançou muito nas últimas décadas, e, no Brasil, esse avanço também ocorreu de forma relevante. Grande parte das decisões judiciais sobre direitos sociais proferidas por juízes e tribunais brasileiros efetivamente corresponde a condenações impostas a órgãos públicos para a adoção de medidas, ações e programas capazes de assegurar positivamente o conteúdo normativo de direitos sociais. Entretanto, a proteção judicial do direito à moradia não está na linha de frente do quadro geral da tutela jurisdicional dos direitos sociais. No Brasil, o número e a qualidade das decisões judiciais envolvendo o direito à moradia são muito pouco significativos quando comparamos com a situação de garantia ampla e bastante arrojada do direito à saúde e mesmo do direito à educação.

É razoável admitir que a proteção judicial do direito à moradia tende a ser mais complexa do que a tutela dos direitos à saúde e à educação. A proteção individual, mediante a oferta de uma habitação a uma pessoa ou a um grupo familiar, naturalmente provoca resistência em um cenário em que milhões de pessoas necessitam simultaneamente de acesso à moradia popular. Admitir a tutela judicial individual do direito à moradia poderia levar ao colapso os orçamentos dos entes públicos e promover a disfuncionalidade das políticas

\footnotetext{
${ }^{2}$ A literatura sobre os direitos sociais tornou-se, ao longo das últimas décadas, prolífica e até inesgotável. Podem ser citados como referências valiosas: Robert Alexy, Teoria dos Direitos Fundamentais (2011), Ingo W. Sarlet, A eficácia dos direitos fundamentais: uma teoria geral dos direitos fundamentais na perspectiva constitucional, (2010), Christian Courtis e Victor Abramovich, Los Derechos Sociales como Derechos Exigibles (2004), Rodolfo Arango, El concepto de derechos sociales fundamentales (2005), Gerardo Pisarello, Los derechos sociales y sus garantias: elementos para uma reconstrucción, 2007, Marcus Gouveia dos Santos, Direitos sociais: efetivação, tutela judicial e fixação de parâmetros para a intervenção judicial em políticas públicas (2016), Jeff King, Judging Social Rights (2012) Katharine Young, Constituting Economic and Social Rights (2014).
} 
habitacionais por eles promovidas. A proteção coletiva, mediante imposição condenatória de políticas públicas de habitação popular, ainda que possa oferecer maior racionalidade na discussão da gestão administrativa e financeira de programas de moradia popular, também se depara com o mesmo tema da multiplicidade de pessoas necessitadas de acesso à moradia e dos custos elevados para a implementação de medidas, ações e planos que garantam habitação à população necessitada de modo geral.

Todavia, a tutela judicial mediante decisões condenatórias a obrigações positivas não é a única forma de assegurar a proteção do poder judiciário ao direito a moradia. A literatura e a prática acerca dos direitos sociais reconhecem que a garantia dessas posições jurídicas pode ser feita por meio de outras soluções. Neste artigo, vamos explorar a possibilidade de oferecer proteção ao direito à moradia mediante o acesso a um processo judicial que seja capaz de incorporar e promover adequadamente o debate sobre a questão jurídica do direito à moradia. Nosso objetivo é explorar essa possibilidade a partir da experiência com a conciliação em conflitos possessórios coletivos, adotada no Poder Judiciário do Estado do Rio Grande do Sul a partir de 2015, para depois propormos sugestões para o aperfeiçoamento do modelo.

Antecipando-se ao que passaria a prescrever o artigo 565 do novo Código de Processo Civil, que entrou em vigor em março de 2016, o Tribunal de Justiça do Estado do Rio Grande do Sul implantou, no primeiro semestre de 2015, um projeto piloto para a conciliação de conflitos possessórios coletivos judicializados em Porto Alegre. A criação de instrumentos de solução consensual de litígios possessórios coletivos, urbanos e rurais, já havia sido definida como uma diretriz de atuação do Poder Judiciário brasileiro desde a edição da Resolução n. 110 do Conselho Nacional de Justiça, do ano de 2010, em cujo texto registra-se a compreensão das peculiaridades sociais, políticas e jurídicas dessa espécie de litígio judicial, a importância da construção de mecanismos de solução consensual desses conflitos e a necessidade de interlocução do Poder Judiciário com outros segmentos do Poder Público para a busca de soluções eficazes para problemas dessa natureza.

O projeto instituído pelo Tribunal de Justiça do Rio Grande do Sul em 2015 foi implantado no âmbito do Centro Judiciário de Solução de Conflitos e Cidadania, o CEJUSC, que funciona em várias comarcas do Estado, incluindo a capital. A constituição de um núcleo para resolução de conflitos fundiários coletivos urbanos decorreu da sensibilidade do Poder Judiciário local em relação à existência e à gravidade da questão das ocupações de áreas urbanas na cidade e para a necessidade de experimentar métodos alternativos de solução de conflitos judiciais em casos dessa espécie. 
No texto que segue, faremos uma síntese da estrutura, dos objetivos, das práticas, dos resultados e dos desafios do projeto nos seus dois anos de funcionamento. O artigo é composto, inicialmente, da exposição de algumas premissas jurídicas que regulam a solução consensual de ações possessórias coletivas no contexto do direito processual instituído pelo Código de Processo Civil de 2015. Adiante, faremos um relatório da estrutura e da experiência de execução do projeto, seguido de uma breve análise acerca das vantagens comparativas do modelo adotado e dos desafios por ele enfrentados para seu prosseguimento e consolidação. Por fim, serão expostas algumas sugestões para o aperfeiçoamento do modelo de conciliação judicial de conflitos possessórios coletivos judicializados.

\section{PREMISSAS JURÍDICAS DA CONCILIAÇÃO JUDICIAL DE LITÍGIOS POSSESSÓRIOS COLETIVOS}

O novo Código de Processo Civil incluiu uma importante novidade na estrutura dos processos judiciais que tratam de litígios coletivos possessórios. Tradicionalmente, o juiz poderia designar audiência de justificação nas ações possessórias. Era o que previa o artigo 928 do Código de Processo Civil de 1973 e é o que prescreve agora o artigo 562 no novo estatuto processual. O novo Código inovou a estrutura das ações possessórias ao criar uma disciplina normativa própria para os litígios possessórios coletivos e ao prever, no seu artigo 565, que o juiz deverá designar audiência de mediação, e não apenas de justificação, sempre que: (i) o esbulho houver ocorrido há mais de ano e dia quando do ajuizamento da ação de reintegração de posse, os chamados casos de "força velha" (art. 565, caput); (ii) quando, tendo sido concedida a medida liminar, não houver sido executada no prazo de um ano, contado da data da distribuição da ação (art. 565, § 1ํ). ${ }^{3}$

Os textos dos dois dispositivos indicam que a designação da audiência de mediação, nas hipóteses referidas, não é uma faculdade do juiz. A redação do caput afirma que o juiz "deverá designar audiência de mediação"; a redação do $\S 1$ 1, por sua vez, dispõe que "caberá ao juiz

\footnotetext{
${ }^{3}$ O CPC manteve a expressão esbulho para significar a invasão de propriedade alheia. No texto, vamos empregar exclusivamente a expressão ocupação, utilizada atualmente para significar o fenômeno social urbano muito mais complexo consistente no ingresso de coletividades de pessoas em áreas urbanas públicas e privadas para fins de moradia, causado pela ausência ou insuficiência de políticas públicas de acesso à habitação popular. A Lei n. 11.977/2009 denominava as ocupações de assentamentos; já a recente Lei n. 13.465, de 11 de julho de 2017, as denomina de núcleo informal urbano. Contudo, o artigo 11, III, da lei designa como ocupante "aquele que mantém poder de fato sobre lote ou fração ideal de terras públicas ou privadas em núcleos urbanos informais", o que revela a popularização da expressão ocupação.
} 
designar audiência de mediação". Conquanto a literalidade dos enunciados textuais não seja necessariamente decisiva na interpretação jurídica, quando as expressões neles utilizadas são claras e o uso de outros métodos interpretativos não infirma a compreensão literal, a interpretação "literal" deve ter preferência, em respeito à soberania popular, que se expressa na elaboração de atos legislativos pelos representantes da população. Ao usar de forma imperativa os verbos dever e caber no caput e no $\S 1$ ㅇdo art. 565, o novo Código de fato institui um comando ao órgão judicial na condução dos processos que tratem de litígios possessórios coletivos e que se encaixem nas situações referidas nos enunciados. Isto é, encontrando-se diante das hipóteses legais, o juiz da causa está obrigado a designar a audiência de mediação. Não se trata, pois, de mera faculdade judicial.

Agora bem, se o juiz tem o dever de designar audiência de mediação judicial nas ações que envolvem litígio possessório coletivo e se enquadrem nas citadas hipóteses legais, é possível afirmar que os ocupantes da área sub judice e réus da demanda possessória têm um direito subjetivo à mediação judicial. Essa parece ser uma novidade de extrema relevância no âmbito da garantia jurídica do direito fundamental à moradia. Com efeito, é razoável admitir que a ratio legis da modificação da estrutura do processo das ações possessórias promovida pelo novo Código, com a introdução da mediação compulsória em caso de litígio possessório coletivo, reside exatamente na percepção de que as ocupações coletivas de áreas urbanas envolvem, de modo geral, uma questão de acesso à moradia popular, e, por isso, representam um instrumento de proteção judicial do direito fundamental à moradia.

A interpretação do texto legal que estamos propondo tem, portanto, duas premissas. A primeira afirma que o juiz da ação possessória que discute litígio coletivo tem o dever de designar audiência de mediação se o caso recair em uma das hipóteses legais, e que, por via de consequência, os ocupantes da área litigiosa têm um direito subjetivo à realização da audiência de mediação. A segunda premissa afirma que esta audiência de mediação é uma nova forma de proteção judicial do direito fundamental à moradia. Como dissemos na introdução, um dos desafios que a positivação do direito à moradia impôs à ciência e à prática jurídicas consiste na definição de mecanismos adequados de tutela judicial do direito. Pois bem, a audiência de mediação nas ações possessórias que tratem de ocupações urbanas parece apresentar-se como uma nova alternativa de garantia jurisdicional do direito à moradia.

É importante atentar para a importância que o Código atribuiu a essa audiência de mediação. Enquanto a tradicional audiência de justificação das ações possessórias conta apenas com a presença do autor, suas testemunhas e o réu, para a audiência de mediação de litígios 
possessórios coletivos devem ser intimados: (a) Ministério Público (§ 2o do art. 565), (b) Defensoria Pública (§ 2o do art. 565), (c) os órgãos responsáveis pela política urbana da União, Estados e Municípios ( $\$ 40$ do art. 565). ${ }^{4}$ Claramente o propósito da audiência é a de tentar encontrar uma solução adequada para o problema de moradia dos ocupantes, seja mediante um acordo com o próprio autor da ação, seja mediante a intervenção de órgãos públicos para oferta de uma alternativa habitacional. Nesse sentido a posição de Luiz Guilherme Marinoni, Sérgio Cruz Arenhart e Daniel Mitidiero:

Logicamente, essa ampla participação pública e dos envolvidos visa assegurar uma solução ampla para o problema, comprometendo também o Poder Público com a solução da questão - que extravasa os limites de uma simples controvérsia particular, refletindo para dimensões política e social muito mais importantes. Supõe o legislador que, efetivamente, o Poder Público estará engajado nessa solução e poderá protagonizar resposta muito mais adequada do que a simples resolução judicial da controvérsia. (MARINONI, ARENHART e MITIDIERO, 2015, p. 176)

Ou seja, o novo Código parece comprometer o juiz da ação possessória com o propósito de utilizar a mediação judicial para procurar um meio de tutelar de forma mais adequada possível o direito à moradia dos ocupantes da área em litígio, independentemente do futuro julgamento de mérito acerca da questão possessória sub judice.

A partir dessas premissas, é possível dar um passo adiante e reconhecer também que sequer há razão para limitar o alcance da solução consensual nas ações possessórias coletivas aos casos enumerados no caput e no parágrafo 1 으 do artigo 565 do código. De fato, se a audiência é uma forma processual de oferecer proteção ao direito fundamental à moradia, ainda que se trate de ação possessória coletiva de força nova poderá o juiz da causa realizar a audiência conciliatória, valendo-se do princípio da consensualidade, incorporado ao Código nos artigos 3ำ, § 3ำ e 139, V. Nesse sentido a correta posição de Vilson Rodrigues Alves:

Ressalvada hipótese em que se comprova com a petição inicial o pleno atendimento à função social da posse pelo autor, com reação imediata contra a ofensa coletiva a essa posse, quanto menos nova seja a força contra a posse, tanto mais se justifica a prévia designação de audiência para a tentativa de solução consensual do conflito possessório coletivo, independentemente de ter-se atingido o trato temporal do ano e dia, Jahr und Tag: a função

\footnotetext{
${ }^{4}$ Sobre a participação destes órgãos na audiência de conciliação prevista no artigo 565 do CPC de 2015, ver Vilson Rodrigues Alves, Ações possessórios individuais e coletivas no CPC de 2015 (2017, p. 815-831).
} 
social da posse esbulhada acaso tivesse diminui de vulto na proporção do distanciamento da força no espaço-tempo social! (ALVES, 2017, p. 792)

Com razão o autor complementa afirmando que apenas uma interpretação estritamente literal dos enunciados legais excluiria a possibilidade de realização de audiência para composição consensual nos casos de litígio coletivo de posse nova. O uso do argumento $a$ contratio sensu poderia ser mobilizado para afirmar que, na medida em que a lei prevê a realização de audiência apenas nos casos enumerados no art. 565, então, na hipótese de ação de posse nova, não caberia a audiência. Sem embargo, como dissemos, tanto o princípio da consensualidade, que caracteriza o novo direito processual civil a partir do CPC de 2015, quanto a compreensão de que a audiência judicial de conciliação é modo de proteção do direito à moradia, conduzem à conclusão de que a realização da audiência pode ocorrer inclusive quanto se tratar de ocupação coletiva de posse nova, ainda que, nesta situação, o juiz tenha apenas a faculdade, porém não o dever de realizá-la, como ocorre nas hipóteses descritas expressamente no artigo 565.

A propósito, convém ressaltar que a exigência legal de realização de audiência judicial de mediação em litígios possessórios coletivos está em consonância com as observações do Comentário Geral n. 07 ao Pacto Internacional de Direitos Econômicos, Sociais e Culturais, produzido pela Comissão de Direitos Humanos da Organização das Nações Unidas, cujo parágrafo 16 propõe que, mesmo nos casos de despejos legalmente justificados, deve ser assegurada "uma autêntica oportunidade processual para que se consultem as pessoas afetadas" (OSÓRIO, 2014, P. 58). Ou seja, o comentário prescreve a realização de audiência judicial na qual os ocupantes possam ser ouvidos, ter seu caso narrado e considerado, tanto fática quanto juridicamente, antes de qualquer decisão judicial, especialmente quando couber ordem de despejo, como ocorre nas ações possessórias. ${ }^{5}$

Conforme dissemos, a garantia de realização de audiência judicial pode ser agora considerada uma forma procedimental de proteção do direito à moradia, acrescida ao conteúdo normativo deste direito. Como acontece com os direitos fundamentais em geral, o direito à moradia é dotado de um conteúdo normativo complexo, do qual podem ser extraídos diversos efeitos jurídicos (SARLET, 2014). ${ }^{6}$ A sua eficácia nuclear consiste no dever do Poder

\footnotetext{
${ }^{5}$ Para um exame do Comentário n. 07 ao PIDESC, ver Jessie Hohmann, The Right to Housing: Law, Concepts, Possibilities (2013, p. 20-28).

${ }^{6} \mathrm{O}$ conceito de direito fundamental como um todo ou completo é elaborado dogmaticamente com mais precisão por Robert Alexy, Teoria dos Direitos Fundamentais (2011, p. 248-253) e, no Brasil, por Ingo Wolfgang Sarlet, Curso de Direito Constitucional (2012, p. 313-314).
} 
Público de prover o acesso à moradia adequada para uma determinada coletividade de pessoas carentes, que não possuem recursos para obterem moradia por seus próprios esforços, por meio da instituição de políticas públicas de acesso à habitação popular. Todavia, podemos também identificar outros efeitos jurídicos do direito à moradia adequada, como o dever de regularização fundiária e urbanística de loteamentos irregulares e clandestinos, de regularização fundiária e urbanística de ocupações consolidadas em áreas públicas e privadas, o dever de reassentamento adequado de pessoas legalmente removidas de áreas ocupadas, 0 dever de assegurar a posse, a vedação de remoções forçadas (MELLO, 2017, p. 456). Pois bem, o direito a uma audiência de conciliação nas ações judiciais que envolvam conflito possessório coletivo pode também ser reconhecido como uma eficácia jurídica agora incorporada ao conteúdo normativo do direito fundamental à moradia. Embora essa eficácia procedimental não possa substituir a garantia material do direito à moradia, que assegure, por exemplo, ações, medidas e programas públicos de acesso à moradia adequada, é possível afirmar que ela possui um valor intrínseco, na medida em que promove o acesso à justiça para pessoas em situação de vulnerabilidade habitacional e de insegurança na posse.

É a partir dessas premissas jurídicas instauradas pela nova ordem jurídico-processual que vamos inserir a exposição e a análise da experiência de conciliação de conflitos possessórios implantada experimentalmente pelo Poder Judiciário do Estado do Rio Grande do Sul na cidade de Porto Alegre.

\section{A ESTRUTURA DO PROJETO}

O projeto de conciliação de conflitos possessórios urbanos coletivos criado pelo Tribunal de Justiça do Rio Grande do Sul é coordenado por um juiz conciliador, que preside a equipe permanente e as sessões de conciliação. A equipe é composta por um representante do Ministério Público, um representante da Defensoria Pública, um representante da Procuradoria Jurídica do Município e outro do Departamento Municipal de Habitação. A participação de órgão público responsável pela política urbana tendeu a se restringir ao próprio Município e à autarquia responsável pela política habitacional local. Apenas em alguns casos houve participação da secretaria estadual responsável pela política urbana do Estado.

Circunstancialmente, participam também das sessões técnicos do Município, do Estado e do Ministério Público. Além da equipe permanente, participam de todas as sessões os autores 
das ações judiciais e seus advogados e os ocupantes das áreas em conflito e seus respectivos advogados. Em alguns casos o autor da ação era o Ministério Público, caso em que permaneceu na sessão apenas o promotor de justiça titular da ação. Em outros processos o representante dos ocupantes era a Defensoria Pública, porém, nestes casos, o representante da instituição na equipe permaneceu na audiência, tendo em vista que este exerce uma função de imparcialidade no que se refere aos interesses imediatos das partes do processo. Ou seja, a estrutura básica do projeto corresponde aos atores cuja participação está prevista no artigo 565 do Código de Processo Civil.

Em alguns casos compareceram às audiências pessoas ligadas a organismos e movimentos sociais de defesa do direito à moradia. Em alguns poucos casos também estiveram presentes professores e estudantes da Universidade Federal do Rio Grande do Sul. A presença de acadêmicos ocorreu especialmente em dois casos emblemáticos tratados no projeto: as ocupações Lanceiros Negros e Vila Dique. No primeiro, a presença de acadêmicos pareceu ser explicada pela motivação fortemente política do movimento social que promoveu a ocupação, o qual procurou desde o princípio enfatizar que a ocupação tinha como objetivo discutir publicamente a política urbana adotada no Estado e no Município, e não apenas garantir moradia para os participantes individuais da ocupação. A ocupação Vila Dique, por sua vez, é situada nas proximidades do Aeroporto Salgado Filho e que teve grande parte de sua composição reassentada para a ampliação da pista do aeroporto. O remanescente da ocupação vinha sendo objeto de pesquisa de um instituto específico da UFRGS, que procurou amparar com dados técnicos os ocupantes na preparação para as sessões de conciliação do núcleo.

Em algumas sessões vereadores fizeram-se presentes. A presença de vereadores foi absolutamente pontual, tendo ocorrido apenas uma ou duas vezes até o período em que se aproximavam as eleições municipais de 2016; a partir desta data, porém, a participação de políticos aumentou significativamente. Em algumas sessões, os vereadores pediram e receberam a palavra. Com o início do período de propaganda eleitoral, a juíza presidente, com o apoio da equipe, decidiu proibir a participação de candidatos a mandatos eletivos nas eleições para evitar a instrumentalização das audiências como estratégia de campanha eleitoral junto aos ocupantes. Embora tenha havido resistência de alguns candidatos quando comunicados da decisão, a orientação foi mantida. Sintomaticamente, não mais houve tentativa de participação de políticos após a passagem do período eleitoral.

A participação de líderes de entidades e movimentos sociais, acadêmicos e políticos mostrou-se inefetiva nas sessões de conciliação em virtude do caráter essencialmente 
pragmático adotado pela equipe na condução das audiências. A participação desses atores, isto é, líderes de entidades e movimentos sociais vinculados à luta pela moradia, acadêmicos e inclusive lideranças políticas pode ser provavelmente produtiva no assessoramento técnico e jurídico a ser alcançado aos ocupantes durante todo o processo de conciliação que se desenrola no projeto, porém fora das sessões de conciliação. Frequentemente os ocupantes necessitam de informações sobre viabilidade urbanística e ambiental para a regularização fundiária das ocupações, e esses dados podem ser produzidos e fornecidos pelos referidos atores. Noutras ocasiões, quando a desocupação da área é inevitável, eles podem auxiliar os ocupantes na apresentação de propostas de soluções para o reassentamento ou para o atendimento temporário dos ocupantes. No curso das audiências, contudo, a participação desses atores parece ser improdutiva, salvo na condição de espectadores.

A participação dos ocupantes foi sempre motivo de atenção por parte da juíza coordenadora do projeto. A sala destinada às sessões de conciliação comporta a presença de pouco mais de vinte pessoas. As ocupações são compostas invariavelmente de um número muito maior de pessoas, quase sempre de centenas e, algumas delas, milhares de ocupantes. 0 modelo resolutivo adotado nas audiências não parece compatível com uma presença aberta e ampla dos membros da ocupação, sobretudo em virtude do elevado risco de dispersão e descontrole dos debates. Assim, os ocupantes são estimulados a serem representados pelas suas lideranças pré-constituídas. Não foi comum tratar com ocupações dotadas de lideranças solidamente pré-constituídas. Assim, normalmente a primeira audiência é utilizada para explicar aos membros da ocupação os objetivos do projeto e para sensibilizá-los a constituírem lideranças que possam representá-las nas sessões de conciliação. Com frequência foi possível observar a dificuldade das ocupações de superar as divergências internas entre grupos. Outras vezes, os interessados em exercer essa liderança não foram capazes de obter apoio significativo dos membros da ocupação. De modo geral, contudo, as ocupações conseguiram constituir representantes suficientemente legitimados para os debates.

Em relação à condução dos debates nas sessões, como dissemos, a juíza e os demais membros da equipe procuram criar as condições para um diálogo pragmático e resolutivo entre proprietários e ocupantes. Na linguagem desenvolvida por Jürgen Habermas, na sua teoria do agir comunicativo, busca-se conduzir as partes para adotarem uma atitude orientada para 0 entendimento mútuo, e não para o sucesso exclusivo de cada uma das partes da negociação. De acordo com Habermas, a orientação para o sucesso implica uma ação estratégia do debatedor, que ingressa no processo de comunicação usando argumentos, ameaças e seduções que visam 
a conduzir o diálogo exclusivamente para impor seus próprios objetivos. No agir comunicativo, por sua vez, "os atores tratam de harmonizar internamente seus planos de ação e de só perseguir suas respectivas metas sob a condição de um acordo existente ou a se negociar sobre a situação e as consequências esperadas" (HABERMAS, 1989, p. 164-165). Conquanto as partes tendam a adotar uma ação estratégia, uma das mais decisivas funções dos responsáveis pela conciliação consiste precisamente em conduzir as partes permanentemente a adotar o modelo da ação comunicativa. O êxito da conciliação está diretamente associado ao sucesso da adesão à ação orientada para o entendimento mútuo.

\section{O ACESSO AO PROJETO}

O projeto de conciliação de conflitos possessórios coletivos foi pensado e é empregado como uma ferramenta de apoio à jurisdição comum que atua nesta espécie de processo judicial. A estrutura e os objetivos do projeto foram apresentados pelo Tribunal de Justiça aos juízes de Porto Alegre e oferecidos como um mecanismo alternativo de resolução dos processos judiciais que envolvem conflitos coletivos possessórios. Os juízes naturais dos processos não estão, evidentemente, obrigados a submeterem ações desta natureza à atuação do núcleo. A remessa do processo é uma decisão soberana do juiz da causa. Ele próprio pode presidir a tentativa de conciliação no curso do processo, mediante a realização da audiência de mediação prevista no citado art. 565 do Código de Processo Civil ou no exercício da atividade conciliatória prevista no art. 3ㅇ, § 3 o do novo estatuto processual. Entretanto, é possível dizer que, na medida em que o projeto se tornava conhecido, um número cada vez maior de juízes pareceu disposto a confiar no funcionamento do projeto.

Como vimos acima, o artigo 565 do Código de Processo Civil prevê que a audiência de mediação nas ações de reintegração de posse envolvendo litígio possessório coletivo ocorrerá quando a efetiva ocupação (denominada de esbulho no texto legal) houver ocorrido há mais de ano e dia ou quando, concedida a medida liminar, a decisão estiver pendente de execução há mais de um ano. Conquanto a maioria dos casos apreciados pela equipe correspondesse a estas duas situações, a atuação do projeto não está limitada a tais hipóteses, isto é, é possível submeter o processo à conciliação mesmo que, por exemplo, a ocupação tenha ocorrido há menos de ano e dia ou que a medida liminar não cumprida tenha sido concedida há menos de um ano, o que efetivamente ocorreu em algumas situações. 
Quando o juiz natural decide submeter o conflito ao projeto, o processo judicial não sofre qualquer paralisação. A sua tramitação permanece exatamente a mesma. Contudo, é natural que, nos casos em que há ordem judicial de reintegração de posse expedida ou o pedido formulado pelo autor ainda não foi apreciado, a reintegração seja informalmente suspensa e a apreciação do pedido de liminar seja adiada. Esses eventos não fazem parte da sistemática de funcionamento do projeto, embora se possa dizer que ao menos o cumprimento da ordem de desocupação devesse ser suspensa enquanto a conciliação é tentada. Na prática, porém, o risco de haver a reintegração enquanto o conflito está submetido à equipe mostrou-se remoto, seja porque a ordem tende a ser sustada consensualmente no curso da atuação da equipe de conciliação, seja porque o cronograma de cumprimento de mandados de reintegração de posse por parte das forças de segurança do Estado é particularmente lento.

O conflito pode e é submetido à atuação da equipe em qualquer estágio de tramitação do processo judicial. Assim, o projeto recebeu desde processos em que o pedido de reintegração de posse ainda não havia sido apreciado, até casos em que o feito se encontrava na fase de cumprimento de sentença. Em uma única oportunidade postulou-se, e a juíza coordenadora do projeto admitiu a atuação da equipe em um caso que se encontrava ainda sob investigação em um inquérito civil público, que tramitava junto à Promotoria de Justiça de Habitação e Ordem Urbanística da capital. A inclusão do caso no projeto se deu a pedido dos representantes do Ministério Público e da Defensoria Pública que atuam na equipe. Conquanto esta tenha sido a única atuação do núcleo em conflito extrajudicial, a experiência foi suficientemente bem-sucedida para que se possa, em circunstâncias muito bem selecionadas, utilizar o mesmo recurso no futuro.

A submissão do litígio à atuação da equipe tem sido feita preponderantemente por iniciativa do juiz natural do processo. Todavia, o caso pode ser submetido ao projeto a partir de requerimento formulado ao juiz da causa pelas próprias partes do processo judicial, do Ministério Público, da Defensoria Pública e até de outras entidades. Em mais de uma oportunidade, processos foram levados ao projeto por petição conjunta dos representantes das duas instituições que atuam na equipe, formulada nos autos de processos judiciais. Também houve casos de pedidos dos ocupantes, da Comissão de Direitos Humanos da Assembleia Legislativa do Estado e em uma oportunidade do Ministério Público Federal, instituição estranha à atuação stantard do projeto, o que revela que o trabalho do núcleo já vem conseguindo projeção social. Uma maior projeção pode levar outras instituições, especialmente órgãos públicos que atuam na área de moradia e habitação social, como a Caixa Econômica 
Federal, e entidades e movimentos sociais ligados à luta pela moradia a também requererem a atuação da equipe. Em qualquer dessas situações, porém, o processo judicial só é encaminhado à equipe de conciliação por decisão do juiz natural da causa, que pode, a qualquer tempo, retirar o processo do projeto.

No primeiro ano de atuação do projeto, em 2015, foram submetidos à atuação da equipe apenas processos judiciais que tratavam de conflitos possessórios coletivos entre pessoas privadas. A partir do segundo ano passaram a ser aceitos também processos envolvendo órgãos públicos e ocupantes privados. Foram atribuídos ao projeto ações movidas pelo Município de Porto Alegre, pelo Departamento Municipal de Habitação de Porto Alegre e pelo Estado do Rio Grande do Sul. Eventualmente houve a inclusão de ações civis públicas movidas pelo Ministério Público tratando de ocupações urbanas, porém, a experiência não foi suficientemente exitosa. Essas ações visam sempre à regularização fundiária e urbanística de ocupações urbanas ou o reassentamento dos ocupantes, quando a regularização é inviável. Ocorre que o Município, réu nas ações, comunicou que não conciliaria em causas desta natureza. Ainda assim, não houve uma decisão pela exclusão definitiva dessa possibilidade.

A sistemática inicial de funcionamento do processo de conciliação foi concebida para a realização de duas ou três audiências. A primeira audiência apresenta o projeto, a equipe e os objetivos a serem perseguidos pelos participantes; a seguir, examina-se a possibilidade de prosseguir com a tentativa de conciliação; caso seja prima facie viável o acordo, a equipe estimula os ocupantes a constituírem lideranças e formularem propostas de solução. Nas audiências seguintes, procura-se obter o acordo. Na medida em que o projeto foi sendo executado, foi-se percebendo como possível e necessária a realização de outras audiências, de modo que não há mais um limite de audiências conciliatórias. O parâmetro utilizado é a real perspectiva de conciliação entre as partes. Também não há uma regra estrita para definir a distância temporal entre as audiências, mas, por vezes, algumas semanas entre as audiências são necessárias, especialmente para a organização da cooperativa ou da associação, para o convencimento dos ocupantes a aderirem a uma proposta de compra e para a realização de estudos de viabilidade de uma futura regularização fundiária e urbanística do assentamento.

\section{AS SOLUÇÕES APRESENTADAS}

Considerando que o projeto foi concebido como uma instância de conciliação de conflitos possessórios de natureza coletiva, naturalmente a grande maioria dos processos 
judiciais submetidos ao projeto corresponde a ações de reintegração de posse, movidas pelos proprietários públicos ou privados de áreas urbanas. Foram também apreciadas ações reivindicatórias e, como vimos, ações civis públicas que tratavam de regularização fundiária e urbanística de ocupações urbanas.

O objetivo imediato da atuação da equipe é formal e consiste na obtenção de uma solução consensual para o conflito entre o proprietário da área ocupada e seus ocupantes. Contudo, é possível afirmar que o objetivo material primordial da atuação é a tentativa de encontrar um modo de garantir a permanência dos ocupantes nas áreas ocupadas. Esse objetivo primordial está em consonância com o art. 10, III, da recentíssima Lei n. 13.465, de 11 de julho de $2017 .^{7}$ Somente residualmente, em caso de insucesso da solução preferencial, a equipe tenta obter um acordo de desocupação pacífica e humanitária.

Quando se trata de conflito coletivo entre pessoas privadas, a principal solução oferecida na conciliação é a mediação para a aquisição da área ocupada por parte dos ocupantes. Na primeira audiência, a juíza questiona o proprietário se ele possui interesse na venda do terreno e se os ocupantes têm interesse na compra; caso as partes externem interesse na negociação, abre-se a etapa de mediação. Nesse caso, os ocupantes são incentivados a constituírem cooperativa habitacional ou associação de moradores que tenha condições de adquirir a totalidade da área ocupada, para que depois possa requerer a regularização fundiária da gleba adquirida junto ao órgão competente do Município. O Departamento Municipal de Habitação de Porto Alegre dispõe de especialista em constituição de cooperativas habitacionais, sendo que este profissional não apenas acompanha as sessões, como está à disposição das partes para orientação na formação deste tipo de entidade. Por razões óbvias não se oferece aos ocupantes a possibilidade de compra dos terrenos que ocupam individualmente, já que, não havendo o prévio parcelamento da gleba, a regularização fundiária seria inviável.

As áreas ocupadas são, com frequência, de grandes dimensões; além disso, muitas vezes são situadas em regiões urbanas valorizadas, portanto, possuem alto valor de mercado. Por isso, a negociação para a aquisição da área pelos ocupantes precisa enfrentar a dificuldade dos ocupantes em se comprometerem com o pagamento de uma dívida de alto valor.

\footnotetext{
${ }^{7} \mathrm{O}$ dispositivo contém a seguinte redação:

Art. 10. Constituem objetivos da Reurb, a serem observados pela União, Estados, Distrito Federal e Municípios:

III - ampliar o acesso à terra urbanizada pela população de baixa renda, de modo a priorizar a permanência dos ocupantes nos próprios núcleos urbanos informais regularizados;
} 
Geralmente, os proprietários que aceitam vender a área têm se mostrado flexíveis em relação ao valor de venda das áreas ocupadas. Eles percebem a dificuldade em obter a devolução da área e, assim, tendem a aceitar um valor menor do que o suposto valor de mercado da gleba. A principal dificuldade parece ser, de fato, a incapacidade financeira dos ocupantes para efetuar o pagamento. Como não existem linhas de financiamento em instituições financeiras para este tipo de negócio, a compra precisa ser feita integralmente com recursos próprios. Os acordos bem-sucedidos envolveram sempre o pagamento parcelado do valor do negócio. A cooperativa ou a associação constituída pelos moradores adquire a totalidade da área ocupada, comprometendo-se a pagar o valor total da gleba em prestações, e cada morador comprometese a pagar à cooperativa ou à associação o valor da sua respectiva parcela mensal pelo mesmo tempo ajustado com o vendedor. Após a aquisição, a entidade constituída requer a regularização fundiária junto à Prefeitura Municipal. Feito o acordo, o processo é devolvido ao juiz da causa.

Nas situações em que o proprietário da área não demonstra interesse na venda, ou a negociação fracassa e existe decisão judicial de reintegração de posse em vigor, a equipe procura intermediar a desocupação pacífica dos moradores. Nesse caso, o principal argumento de convencimento para a conciliação consiste na concessão de um prazo razoável para que os ocupantes desocupem a área. Nesse momento, os representantes do Município são instados a participarem ativamente do processo de desocupação, mediante a proposição de soluções alternativas para os ocupantes, como o reassentamento dos ocupantes e a oferta de aluguel social. Infelizmente, como veremos depois, a resistência dos órgãos públicos em atuarem nas negociações para desocupação pacífica tem sido um dos grandes entraves encontrados pela equipe, e explica a baixa taxa de êxito desse tipo de solução no projeto. De qualquer forma, inexitosa a conciliação para desocupação pacífica, o processo é devolvido ao juiz natural.

Quando se trata de conflito coletivo envolvendo área pública, a equipe procura inicialmente identificar se existe alguma possibilidade de regularização fundiária e urbanística da ocupação, ou seja, a equipe prioriza a permanência dos ocupantes na área ocupada. Com frequência ficou evidente para os membros da equipe que esta era a solução adequada, normalmente por tratar-se de assentamento antigo e consolidado, pelas características da área ocupada e pela ausência completa de perspectiva de outra destinação da gleba. Entretanto, nenhum acordo de regularização de ocupação em área pública foi realizado no projeto até este momento, já que tanto o Município quanto o Estado adotaram como postura institucional no projeto recusar-se a aceitar a permanência dos ocupantes nas áreas ocupadas. Por outro lado, é 
possível dizer que a exposição pública do contexto da ocupação nas sessões constrange o órgão público a repensar a desocupação.

O argumento padrão apresentado pelos estes estatais para rejeitar a regularização é, nos parece, perfeitamente compreensível. Os representantes dos órgãos públicos alegam que a anuência à permanência da ocupação em alguns casos geraria, por um lado, um problema de isonomia no tratamento das ocupações, que só seria solucionável com uma inviável admissão de regularização de todas as ocupações de áreas públicas; e, por outro lado, representaria um estímulo a novas ocupações de terrenos públicos, na medida em que criaria a expectativa de regularização futura. Conquanto o argumento seja dotado de razoabilidade, ele parece ser superável pela adoção de critérios técnicos, uniformes e transparentes para a eleição das ocupações regularizáveis. Em muitos dos casos de ocupações de áreas públicas a permanência dos ocupantes e a regularização do assentamento pareceu ser a melhor solução inclusive para o poder público, já que se tratava de ocupações consolidadas, adaptadas à região urbana em que se encontram e sem perspectiva de outra destinação por parte do órgão público.

Como tanto o Município quanto o Estado se recusaram sistematicamente a negociar a regularização de ocupações em áreas públicas, nestes casos o projeto só pode oferecer como solução conciliatória a desocupação pacífica da área, mediante a fixação de um prazo razoável para a saída dos ocupantes. Também nos casos de ocupações de áreas públicas os órgãos estatais se recusaram a colaborar efetivamente no reassentamento dos ocupantes. A rigor, a única oferta apresentada pelos entes públicos para os ocupantes em caso de desocupação pacífica foi a concessão de aluguel social. Não sendo bem-sucedida a conciliação para desocupação, o processo é devolvido ao juízo original.

\section{ANÁLISE CRÍTICA DOS RESULTADOS PARCIAIS DO PROJETO}

A prática da conciliação de conflitos possessórios coletivos judicializados tem mostrado vantagens comparativas entre a atuação do projeto em relação à forma convencional de abordagem judicial dos litígios possessórios, porém também tem revelado muitos desafios atuais e potenciais para o êxito dos propósitos do projeto adotado pelo Tribunal de Justiça do Estado do Rio Grande do Sul. A seguir, listaremos duas vantagens comparativas e, a seguir, três dos desafios imediatos com que o projeto se depara, escolhidos pela sua relevância para o próprio futuro da proposta. Entre as vantagens que observamos na atuação do projeto podem ser referidas as seguintes: 


\section{Desenvolvimento de expertise nas questões envolvendo a relação entre} ocupações coletivos e direito à moradia

O contato sistemático com os casos de litígio possessório coletivo e com seus principais envolvidos, ocupantes, proprietários e agentes públicos responsáveis pela política habitacional, permitiu aos membros da equipe o desenvolvimento de um conhecimento mais aprofundado de questões jurídicas, administrativas e técnicas acerca da história, das causas e das consequências das ocupações urbanas, bem como das possibilidades e dos limites de soluções, como regularização fundiária e urbanística, políticas habitacionais, reassentamento, remoção forçada, segurança na posse, concessão de benefícios administrativos (como, por exemplo, aluguel social), formação de cooperativas e associações com finalidade habitacional. A aquisição dessa expertise ocorreu precisamente pelo contato sistemático com a realidade das ocupações no curso das sessões, os quais conferem aos membros da equipe uma singular confiança no processo de conciliação. Tais virtudes não são facilmente reproduzíveis pelos juízes naturais dos processos judiciais, que possuem um contato atomizado com este contexto bastante complexo. É possível afirmar, assim, que há claras vantagens em submeter as ações possessórias coletivas à atuação do projeto em relação à atuação atomizada de diversos juízes. No limite, essa vantagem recomendaria a criação de uma vara especializada ou, ao menos, a centralização das ações dessa natureza em um único juízo.

\section{Desenvolvimento de um conhecimento sistêmico do problema das ocupações coletivas de áreas urbanas}

A multiplicidade de casos submetidos ao projeto também permitiu aos membros adquirir uma compreensão sistêmica ou global do problema das ocupações coletivas urbanas no Município de Porto Alegre. O modelo de atuação pulverizado nas diversas varas judiciais da Capital apresenta ao juiz cada caso de ocupação urbana como único ou representativo de uma região, o que impede que ele tenha a visão da generalidade do problema, com suas múltiplas e complexas causas e consequências. É possível afirmar que a atuação pulverizada tende a induzir os juízes a tratar esses casos a partir do modelo tradicional de repressão ao esbulho da propriedade privada, sem atentar para a gravidade da questão do acesso à terra urbana que está na origem das ações de ocupação. A forma de atuação do projeto permite visualizar as áreas mais vulneráveis e conflagradas, os diversos agentes que atuam na origem das ocupações, as semelhanças e diferenças entre os participantes das ocupações, as soluções habitacionais 
regulares e irregulares disponíveis na cidade, de tal forma que tem sido possível desenvolver uma espécie de "inteligência das ocupações" a partir do conhecimento sistêmico desse fenômeno. Essa inteligência claramente se apresenta como uma vantagem da atuação concentrada da equipe vis-à-vis a atuação atomizada nas diversas varas judiciais da Capital.

Por outro lado, entre os grandes desafios, podem ser citados os seguintes:

\section{A organização dos ocupantes para participarem ativamente da conciliação e para proporem e cumprirem as soluções negociadas e obtidas no projeto}

As audiências têm mostrado que a quase totalidade das ocupações são desorganizadas e carentes de qualquer organicidade. Mesmo quando a ocupação foi originalmente promovida e conduzida por movimentos sociais e lideranças políticas ou comunitárias, ao longo do tempo e, especialmente, na medida em que o assentamento se adensa, a organização é perdida. Assim, ao serem instados para participar do projeto, os ocupantes não fazem parte de uma comunidade com algum grau de organização social. Normalmente se trata de um agregado de pessoas unidas pela situação fática aleatória de ocuparem um mesmo assentamento irregular, nada além disso. Essa característica das ocupações reduz a capacidade dos ocupantes de participarem eficientemente das sessões de conciliação e de se posicionarem em relação às soluções apresentadas pela equipe do projeto e pelos demais interlocutores. É possível dizer que os movimentos sociais de luta pela moradia prestarão uma grande contribuição se forem capazes de auxiliar os moradores de ocupações na sua organização para participarem ativa e eficientemente da conciliação judicial.

\section{O elevado risco de inadimplência do valor da compra da área ocupada por parte das cooperativas e associações de moradores}

Este seguramente é um dos maiores desafios para o futuro da conciliação judicial de conflitos possessórios coletivos em áreas privadas. A falta de organicidade das ocupações, a extrema volatilidade dos moradores de assentamentos, a renda baixa e instável dos ocupantes, a fragilidade das lideranças e a potencial ineficiência jurídica das punições pelo incumprimento das obrigações assumidas torna exponencial o risco de inadimplência das prestações assumidas pelas cooperativas ou associações em caso de aquisição das áreas privadas ocupadas. Como os valores das áreas são muito elevados e o poder aquisitivo dos ocupantes é muito precário, os valores de compra e venda são divididos em muitas parcelas, normalmente em vários anos; assim, há um grande risco de desmobilização dos moradores das ocupações e das próprias 
cooperativas e associações ao longo do tempo, frustrando os propósitos da conciliação. Sem que essa questão seja bem resolvida, o projeto pode estar induzindo os proprietários a venderem suas áreas sem qualquer garantia de efetivo pagamento do valor do negócio. Além disso, a reintegração judicial da posse ter-se-á inviabilizado, seja porque houve a venda da área, e, portanto, terá feito do vendedor o titular apenas de um direito de crédito, seja porque, ainda que mantido o direito à reintegração no acordo, o proprietário terá enorme dificuldade com a definição das áreas a serem reintegradas, considerando que muitos ocupantes terão pago suas parcelas e, assim, não estarão sujeitos à desocupação.

\section{A baixa adesão dos entes públicos aos objetivos centrais do projeto}

Nos dois anos do projeto, o Município de Porto Alegre, o Departamento Municipal de Habitação e o Estado do Rio Grande do Sul participaram ativamente das sessões de conciliação, fazendo-se representar por profissionais competentes e interessados, de forma permanente ou sempre que solicitados. Entretanto, no que concerne à participação efetiva nas soluções propostas pela equipe do projeto ou pelas partes do processo, a atuação dos entes públicos pode ser classificada de desapontadora. Nos conflitos de áreas privadas, Município e DEMHAB não foram além de, eventualmente, propor o pagamento de aluguel social em caso de desocupação pacífica do assentamento, ou de aceitar um alongamento do prazo de desocupação. Em nenhum caso um órgão público se dispôs a promover o reassentamento dos ocupantes. O auxílio para a formação de cooperativas por parte do DEMHAB pode ser citado como uma forma permanente, porém pouco intensa, de participação de órgãos públicos. Quando se tratou de áreas públicas, a única postura adotada pelos entes estatais foi insistir na desocupação, normalmente mediante o argumento da quebra de isonomia e do perigo de incentivo a novas ocupações, conforme já registramos. Aparentemente, a baixa adesão dos órgãos públicos resulta: (i) da indiferença ou da incompreensão dos gestores políticos acerca do projeto em si e de suas potencialidades para resolver conflitos fundiários urbanos; (ii) da indiferença ou da incompreensão dos gestores públicos acerca da natureza e da dimensão do próprio problema das ocupações urbanas na capital do Estado; (iii) da falta de vontade política de apoiar o projeto. Considerando que a atuação do poder público é indispensável para a resolução de grande parte dos conflitos possessórios coletivos apreciados pelo projeto, tanto de áreas públicas quanto de áreas privadas, o impasse em relação à baixa intensidade da participação dos entes estatais pode representar o risco de ineficiência global do projeto. 
Em relação a este último desafio, é possível conjecturar que a edição da Lei n. 13.465, de 11 de julho de 2017, tem o potencial alterar positivamente a atitude dos órgãos públicos quanto a sua atuação no projeto e nas audiências de mediação do artigo 565 do Código de Processo Civil. Isso porque a nova lei modifica substancialmente a regularização fundiária no direito brasileiro, criando vários institutos que visam a facilitar a regularização dos chamados núcleos informais urbanos, em áreas públicas e privadas, tais como: (i) a legitimação fundiária e a legitimação de posse (essa já existente desde a Lei n. 11.977/2009), (ii) a intervenção do poder público em parcelamento irregular ou clandestino, (iii) a legitimidade para requerer a regularização administrativa atribuída a várias instituições, como Ministério Público e Defensoria, aos membros das ocupações, individual ou coletivamente, e inclusive aos responsáveis por parcelamento irregular e clandestino, e (iv) a resolução consensual dos conflitos no âmbito do processo administrativo de regularização fundiária. A nova lei concede claro protagonismo ao Município no processo de regularização fundiária de ocupações urbanas, o que pode representar uma mudança significativa para a efetividade da atuação destes entes estatais nas ações judiciais que tratam de litígios possessórios coletivos.

\section{PROPOSTA DE UM MODELO DE ATUAÇÃO JUDICIAL}

O modelo de atuação judicial em casos de conflitos coletivos possessórios entre Estado e ocupantes que tem recebido mais atenção e aceitação internacional foi estabelecido pela Corte Constitucional da África do Sul na apreciação do caso Occupiers of 51 Olivia Road, de 2008, celebrado internacionalmente como um paradigma de atuação judicial na proteção do direito à moradia adequada. ${ }^{8}$ Nesse caso, a corte sul-africana ordenou ao Poder Público e aos ocupantes que eram parte da ação a adoção do que chamou de "engajamento significativo" (meaningful engagement), isto é, de um comprometimento efetivo entre eles para o estabelecimento de um diálogo visando a procurar soluções adequadas e aceitáveis para ambas as partes.

O caso concreto tratava da remoção de 400 pessoas de dois prédios situados na área central de Johannesburg, ocupados desde 1998. Na apreciação do caso, a Corte Constitucional sul-africana destacou o fato de que o Poder Público da cidade, antes de executar o despejo administrativo das edificações ocupadas, deveria ter considerado que as pessoas despejadas

\footnotetext{
8 Para exposições e análises da decisão, ver Jessie Hohmann, The Right to Housing: Law, Concepts, Possibilities (2013, p. 101-103), e Jeff King, Judging Social Rights (2012, pp. 105, 174, 274, 76, 283, 297 e 300).
} 
tornar-se-iam sem-teto (homeless) como resultado da ação. Nessas circunstâncias, afirmou a Corte, a municipalidade "deveria no mínimo ter-se engajado significativamente com os ocupantes, individual e coletivamente", para evitar essa consequência incompatível com a dignidade humana.

Na decisão, a Corte entendeu que os objetivos deste engajamento significativo deveriam ser, pelo menos, os seguintes; (a) avaliar as consequências do despejo; (b) verificar se o Poder Público poderia ajudar a aliviar as consequências mais dramáticas do despejo; c) estudar se seria possível manter os prédios ocupados em condições relativamente seguras e salubres por um período provisório; d) avaliar se o Município teria obrigações com os ocupantes nas circunstâncias específicas; e) verificar quando e como o Município poderia satisfazer tais obrigações. Além disso, a Corte também enfatizou que o Município deveria levar em consideração que estava lidando com pessoas pobres e vulneráveis, que poderiam resistir a participar do diálogo. Ainda assim, o Poder Público deveria adotar medidas adequadas para insistir na tentativa de encontrar soluções consensuais.

De acordo com o tribunal, quando o Poder Público lida com pessoas sem-teto, ele deve levar em conta que incidem na situação tanto o direito geral à dignidade humana (artigo 10 da Constituição da África do Sul) e o direito à moradia (artigo 26(2) da Constituição sul-africana). Por força desses direitos, a ação do Poder Público deve pautar-se pelo princípio da razoabilidade. Em algumas circunstâncias, segue a decisão, "pode ser razoável disponibilizar às pessoas moradia permanente, e, em outras, não prover qualquer moradia. Entre estes dois extremos, as possibilidades são quase infinitas". De qualquer forma, sempre que a desocupação levar à consequência de tornar os despejados pessoas sem-teto, o Estado deve engajar-se significativamente com eles com base nos objetivos acima referidos.

Por outro lado, a Corte ressaltou que os ocupantes não podem adotar "uma atitude intransigente e anular o processo de engajamento fazendo exigências não negociáveis e irrazoáveis". Eles devem ser encorajados a adotarem uma postura pró-ativa e não puramente defensiva no processo de negociação. Além disso, "organizações da sociedade que apoiam as reivindicações das pessoas devem preferencialmente facilitar o processo de engajamento de toda a forma possível".

Com base nestes argumentos, a Corte Constitucional ordenou provisoriamente que o Município e os ocupantes negociassem a adoção de medidas adequadas por meio desse processo de "engajamento significativo" e comunicassem ao tribunal os passos adotados e os resultados obtidos, antes de os juízes decidirem o mérito da questão do despejo. Entre as 
medidas adotadas, ocorreu a realização de melhorias imediatas nos prédios ocupados, para torná-los mais habitáveis temporariamente, e o Poder Público providenciou acomodações alternativas para todos os ocupantes de forma provisória, até que fosse possível conceder-lhes assentamento definitivo. Os ocupantes, por sua vez, comprometeram-se a mudar-se paras as acomodações provisórias disponibilizadas. A Corte então homologou o acordo entre as partes e apreciou o mérito do caso, não sendo necessário prosseguir na análise das questões jurídicas então debatidas e decididas.

O modelo de atuação adotado no caso Occupiers of Olivia Road 51 é importante como referência na reflexão sobre a estrutura e a função da conciliação judicial de conflitos possessórios coletivos, porque transfere parte do ônus do impulso da negociação para as próprias partes, em encontros que devem ocorrer fora do ambiente judicial e cujos desdobramentos e resultados devem ser comunicados ao juiz ou ao tribunal responsável pelo caso. A nosso juízo, esse modelo tem o potencial de ser mais efetivo do que aquele adotado até agora no projeto, no qual as ações de conciliação entre as partes ocorrem, geralmente, apenas nas próprias sessões judiciais. A determinação de que as partes ingressem em um diálogo com "engajamento significativo" para construir soluções consensuais e recorram à intervenção judicial apenas em situações de impasse insuperável e para oficializar acordos parciais ou totais parece mais eficiente do que a redução do espaço da conciliação tão somente às próprias audiências judiciais.

Conquanto o caso sul-africano tenha ocorrido em um litígio envolvendo o Poder Público, e sem dúvida o modelo seja mais facilmente empregável quando se trata de ocupação de áreas públicas, nada impede que se o adote também nos casos de ocupação em áreas privadas. Isso porque, conforme já vimos, mesmo nesses casos não é possível encontrar uma solução que respeite minimamente o direito à moradia se não houver a intervenção do Poder Público. Nos casos em que o acordo entre o proprietário privado e os ocupantes tornar-se inviável, o Poder Público pode ajudar mediante a construção de um prazo razoável para desocupação pacífica, total ou parcial da área, reassentamento temporário ou definitivo, obtenção de um espaço para acolhimento e atendimento imediato após o cumprimento da reintegração de posse ou da desocupação pacífica. Todas essas alternativas podem ser debatidas e efetivadas mediante esforços feitos fora do espaço judicial e os seus resultados reportados ao Poder Judiciário, que pode também intervir, como dissemos, para resolver impasses ou dificuldades que surgem no processo de construção das soluções consensuais. 
A nosso ver, esse modelo tem ainda uma vantagem adicional. Na medida em que o órgão judicial determina que as partes envolvidas ingressem em um diálogo com "engajamento significativo", a atuação jurisdicional protege importantes características da ação do Poder Público na garantia e promoção de direitos sociais: a policentricidade e a flexibilidade. Conforme destaca Jeff King, a policentricidade ocorre quando o problema "compreende uma ampla rede de relacionamentos interligados, de tal forma que a mudança em um relacionamento causa uma série de mudanças complexas em outros fatores" (KING, 2012, p. 190). a necessidade de flexibilidade da ação administrativa e judicial na administração em um Estado de Bem-Estar Social complexo é reconhecida pelos atores jurídicos que atuam nesta área. O autor define sinteticamente a flexibilidade como "a capacidade de adaptar-se a circunstâncias imprevistas" (KING, 2012, p. 250-251).

No caso de demandas envolvendo ocupações urbanas e, por conseguinte, o debate sobre a tutela do direito à moradia, a policentricidade se manifesta na necessidade de interveniência de múltiplos departamentos da Administração Pública na operação de equacionamento do problema, como os órgãos de habitação, urbanismo, meio ambiente, planejamento e saneamento básico. E a atuação desses órgãos não pode ser atomizada, pois há necessidade de interação entre eles para a confecção de estudos técnicos, diagnósticos e encaminhamento de soluções para problemas tão variados como risco hidrológico, risco geológico, drenagem pluvial, acesso a equipamentos urbanos. O diálogo e a interação entre esses diferentes departamentos da Administração Pública certamente não pode ocorrer em atos judiciais como audiências e tampouco pode depender exclusivamente de impulso judicial. É preciso que haja um comprometimento efetivo do Poder Público para engendrar soluções policêntricas no interior da esfera administrativa e somente levar a juízo propostas já em estágio avançado de conclusão.

O que estamos denominando de policentricidade, na esteira do que propõe Jeff King, já havia sido destacado como uma peculiaridade de todos os direitos sociais por Gerardo Pisarello. O jurista espanhol assinala que a proteção dos direitos sociais é caracterizada pela intervenção de múltiplos órgãos e instituições, desde órgãos legislativos e administrativos até órgãos de controle externo, como as defensorias do povo (no Brasil, Ministério Público e Defensoria Pública realizam essa função) e tribunais de contas. Adiante, refere Pisarello:

A defesa do caráter multi-institucional da tutela dos direitos sociais deveria conduzir, assim mesmo, à defesa de um sistema multinível de garantias, baseado em um princípio de que, 
nas condições atuais, resulta impossível, além de indesejável, pretender assegurar os direitos sociais em uma única escala de tipo estatal. (PISARELLO, 2017, p. 112)

A flexibilidade, por sua vez, implica a reflexão, a discussão e a decisão por utilizar diferentes instrumentos administrativos, como a concessão de aluguel social, a inscrição em cadastro para acesso a empreendimentos de habitação popular, a colocação em abrigo provisório, a regularização fundiária in situ, o reassentamento parcial ou total dos ocupantes. Normalmente será necessário adequar a solução a ser aplicada no caso sub judice às próprias políticas habitacionais do Poder Público, e, eventualmente, reajustar ou excepcionar essas políticas para oferecer alguma solução ao caso individual. Além disso, os próprios ocupantes necessitam de flexibilidade na definição de seu destino, como a decisão por permanecer ou não no local, escolher entre regularização in situ e reassentamento, organizar-se em cooperativas ou associações.

Por outro lado, o modelo do caso Occupiers of Olivia Road 51 pressupõe e promove outro importante valor do direito processual contemporâneo, a colaboração. De acordo com Daniel Mitidiero, "a colaboração é um modelo que visa dividir as posições jurídicas do juiz e das partes do processo civil, estruturando-o como uma verdadeira comunidade de trabalho" (MITIDIERO, 2015, p. 52). Ao exigir um diálogo engajado e significativo entre as partes envolvidas no conflito possessório coletivo, o órgão judicial estimula os envolvidos a adotarem uma postura colaborativa para a resolução dos diversos problemas fáticos e jurídicos ligados ao conflito. Na verdade, o princípio da colaboração, como o designa Daniel Mitidiero (MITIDIERO, 2015, p. 100) pode ser considerado como implícito nos enunciados normativos do artigo 565 do Código de Processo Civil, na medida em que a previsão de audiência de mediação entre as partes, com a participação do Ministério Público, da Defensoria Pública e dos órgãos públicos responsáveis pela política urbana pressupõe que a atuação das partes e dos demais órgãos implicará uma atitude colaborativa para a resolução do litígio possessório coletivo.

Assim, é possível propor o recurso a este modelo tanto para o aperfeiçoamento da atuação do próprio projeto que expusemos, quanto dos juízes que decidem tentar a mediação na forma do artigo 565 do Código de Processo Civil ou qualquer outra forma de conciliação nas ações que tratam de conflitos possessórios coletivos urbanos. Ao invés de concentrarem todos os esforços conciliatórios nas audiências judiciais, talvez seja mais eficiente impor aos atores envolvidos no conflito o que a Corte Constitucional da África do Sul chamou de engajamento significativo no processo de produção de uma solução consensual, mediante a adoção de um diálogo pragmático simultâneo à tramitação do processo judicial. As audiências judiciais, neste 
caso, seriam utilizadas para (i) dar impulso ao diálogo, (ii) estabelecer as condições do diálogo, (iii) monitorar as atividades dos envolvidos e (iv) para a adoção das intervenções judiciais necessárias para a resolução dos problemas jurídicos gerados pelo litígio.

\section{CONSIDERAÇÕES FINAIS}

Os dois anos e meio de prática do projeto sugerem que a experiência pode representar um espaço decisivo para o aperfeiçoamento dos mecanismos de proteção judicial do direito à moradia, seguramente um dos direitos sociais mais carentes de instrumentos de garantia jurisdicional. A partir da inclusão do artigo 565 do novo Código de Processo Civil na ordem jurídica brasileira, a realização de audiência de conciliação judicial passou a ser um direito subjetivo dos membros de ocupações urbanas, podendo ser considerado um novo elemento do conteúdo normativo do direito fundamental à moradia em sentido amplo. $O$ projeto demonstra oferecer um modelo particularmente eficiente de realização da mediação ou conciliação judicial exigida pelo dispositivo legal citado.

Ressaltamos duas grandes virtudes do modelo: a formação de uma inédita expertise em conciliação de conflitos possessórios coletivos e a construção de um conhecimento panorâmico da situação das ocupações urbanas em Porto Alegre. Essas virtudes foram produzidas precisamente pelo contato sistemático com a realidade das ocupações no curso das sessões e conferem aos membros da equipe uma maior capacidade de entender o problema e propor soluções para resolvê-lo adequadamente. Tais virtudes não são facilmente reproduzíveis pelos juízes naturais dos processos judiciais porque estes atuam de forma atomizada, o que tende a induzi-los a tratar o caso a partir do paradigma tradicional do esbulho possessório. Por isso, é possível concluir que o modelo de conciliação judicial instituído pelo Tribunal de Justiça do Rio Grande do Sul oferece uma maior capacidade de resolver de forma adequada e humanitária os conflitos gerados por ocupações urbanas. Alguns ajustes terão que ser feitos. A adoção do modelo de engajamento significativo entre os envolvidos no conflito para além dos encontros judiciais, derivado da atuação da Corte Constitucional sul-africana, pode representar um possível aperfeiçoamento da forma de atuação da equipe. De qualquer modo, o projeto parece ter se credenciado como uma importante solução alternativa e eficiente de conflitos coletivos possessórios e de efetivação do direito fundamental à moradia. 


\section{REFERÊNCIAS BIBLIOGRÁFICAS}

ALEXY, Robert. Teoria dos Direitos Fundamentais. 2a edição. São Paulo: Editora RT, 2011.

ALVES, Vilson Rodrigues. Ações possessórias individuais e coletivos no CPC de 2015. Campinas: Servanda: 2017.

ARANGO, Rodolfo. El concepto de derechos sociales fundamentales. Bogotá: Legis, 2005.

COURTIS, Christian e ABRAMOVICH, Victor. Los derechos sociales como derechos exigibles. Madrid : Editorial Trotta, 2004.

HABERMAS, Jürgen. Consciência moral e agir comunicativo. Rio de Janeiro: Tempo Brasileiro, 1989.

HOHMAMM, Jessie. The Right to Housing: Law, Concepts, Possibilities. Oxford: Hart Publishing, 2013.

KING, Jeff. Judging Social Rights. Cambridge; Cambridge University Press, 2012.

MARINONI, Luiz Guilherme; ARENHART, Sérgio Cruz; e MITIDIERO, Daniel. Curso de Processo Civil. Vol. 3. São Paulo: RT, 2015.

MELLO, Cláudio Ari. Elementos para uma teoria jurídica do direito à cidade. Revista de Direito da Cidade. Vol. 09, n. 02, p. 437-462.

MITIDIERO, Daniel. Colaboração no processo civil: pressupostos sociais, lógicos e éticos. 3ạ edição. São Paulo; RT, 2015.

OSÓRIO, Letícia Marques. O direito à moradia como direito humano. In.: FERNANDES, Edésio e ALFONSIN, Betania Alfonsin (org). Direito à moradia adequada: o que é, para quem serve, como defender e efetivar. São Paulo: Forum, 2014, p. 39-84.

PISARELLO, Gerardo. Los derechos sociales y sus garantias: elementos para uma reconstrucción. Madrid: Editorial Trotta, 2007.

SANTOS, Marcus Gouveia. Direitos sociais: efetivação, tutela judicial e fixação de parâmetros para a intervenção judicial em políticas públicas. Rio de Janeiro: Lumen Juris, 2016.

SARLET, Ingo Wolfgang, MARINONI, Luís Guilherme e MITIDIERO, Daniel. Curso de Direito Constitucional. São Paulo: Editora RT, 2012.

A eficácia dos direitos fundamentais: uma teoria geral dos direitos fundamentais na perspectiva constitucional. 10a edição. Porto Alegre: Livraria do Advogado, 2010.

Algumas notas sobre a Eficácia e Efetividade do Direito à Moradia como Dirito de Defesa nos Vinte anos da Constituição Federal de 1988. In.: FERNANDES, Edésio e ALFONSIN, Betania Alfonsin (org). Direito à moradia adequada: o que é, para quem serve, como defender e efetivar. São Paulo: Forum, 2014, p. 261-292. 
YOUNG, Katharine. Constituting Economic and Social Rights. Oxford: Oxford University Press, 2014.

Trabalho enviado em 19 de julho de 2017. Aceito em 20 de outubro de 2017. 